\title{
PRECEPTORIA DE RESIDÊNCIA HOSPITALAR NO CONTEXTO DA PANDEMIA DE
}

\section{COVID-19: RELATO DE EXPERIÊNCIA}

\section{Joana Angélica Marques Pinheiro', Antonia Amanda Araújo², Mariana Rodrigues De Araújo Ivna De Moura Brasil Ramos ${ }^{4}$, Ana Virgínia Sales Monte Costa ${ }^{5}$ Vera Lúcia Mendes de Paula $\operatorname{Pessoa}^{6}$ Thereza Maria Magalhães Moreira $^{7}$}

1,2,3,4,5 Hospital Dr Carlos Alberto Studart Gomes, ${ }^{6,7}$ Universidade Estadual do Ceará

DOI: $10.47094 /$ ICONRES.2021/22

Introdução: A necessidade de uma saúde ampliada que priorize assistência especializada e integral à população foi evidenciada com as residências integradas em saúde, modalidade de ensino aprendizagem em serviço, envolvendo diferentes categorias profissionais. No contexto hospitalar a residência possibilita relações transversais e complementares, tendo o preceptor um papel fundamental no direcionamento e aperfeiçoamento do aprendizado ao cuidado integral ao paciente. Com a pandemia de Covid-19, de rápida disseminação, os hospitais se viram obrigados a realizar mudanças estruturais e comportamentais de seus profissionais, incluindo preceptores e residentes. Objetivo: Relatar experiência de preceptoria de residência integrada em saúde, a nível hospitalar, no contexto da pandemia de Covid-19. Metodologia: Relato de experiência de preceptoria, em hospital referência em cardiopneumologia, no contexto da pandemia, com suas restrições e cuidados. Resultados: A pandemia provocou elevada demanda de atendimento hospitalar à pacientes com complicações por Covid-19, com necessidade de suportes tecnológicos e profissionais capacitados, exigindo cuidados rígidos com paramentação, uso de EPIs, normas de convívio e recursos técnicos para promover conforto e benefício a profissionais e pacientes. Preceptores e residentes precisaram se adaptar a essa nova realidade de assistência à beira leito, exigindo habilidade, comprometimento e agilidade na prestação do serviço, atuando próximo aos demais integrantes da equipe, na busca por rapidez e eficiência de cada caso, para favorecer alta precoce e minimizar seqüelas advindas da doença. Conclusão: A atuação de preceptor e residente, no contexto Covid em ambiente hospitalar, precisa ser pautada na parceria, suporte técnico e emocional, interprofissionalidade, celeridade e resolutividade dos casos, possibilitando aprendizado ampliado, cuidado integral e efetivo ao paciente.

Palavras-chave: Residência multiprofissional. Covid-19. Hospital.

Área Temática: Clínico - Hospitalar 